\title{
New antioxidant sesquiterpenes from a culture broth of Coprinus echinosporus
}

\author{
Dae-Won Ki ${ }^{1}$, Dae-Won Kim ${ }^{1}$, Byung Soon Hwang ${ }^{1}$, Seung Woong Lee ${ }^{1}$, Soon-Ja Seok ${ }^{2}$, In-Kyoung Lee ${ }^{1}$ and \\ Bong-Sik Yun ${ }^{1}$
}

The Journal of Antibiotics (2015) 68, 351-353; doi:10.1038/ja.2014.158; published online 17 December 2014

Oxidative stress caused by the disproportionate production of reactive oxygen species (free radicals), as compared with the elimination of these products by endogenous antioxidants, is considered to be one of the main causes in the progression of rheumatoid arthritis, arteriosclerosis, ischemic stroke, autoimmune disease, diabetes, cancer initiation and aging. ${ }^{1-5}$ Thus, an intake of natural antioxidants has been posited to reduce the risk of developing some of these pathologies related to oxidative stress. ${ }^{6}$ During a search for natural antioxidants from fungal strains, we found that the culture broth of Coprinus echinosporus exhibited potent free radical scavenging activity. C. echinosporus is a basidiomycete belonging to the genus Coprinus together with C. comatus, C. cinereus, C. plicatilis and C. radians. The genus Coprinus was reported to produce diverse sesquiterpenes, diterpenoids, triterpenoids and piperidine derivatives, which were reported to exhibit anti-inflammatory, antioxidant, anti-cancer, antibacterial, anti-fungal and cerebral blood flow-improving effects. ${ }^{7-12}$ In this study, we report the isolation and structure determination of novel sesquiterpenes (2-4, Figure 1) and their antioxidant properties.

C. echinosporus KACC52101 was stationary cultured at $27^{\circ} \mathrm{C}$ for 30 days in a tissue culture bottle (1 l) containing $400 \mathrm{ml}$ of potato dextrose broth medium. Fifteen liters of the culture broth were filtered to separate the broth filtrate and the mycelium, and the mycelium was extracted with 0.51 of $80 \%$ aqueous acetone. The acetone extract was filtered, and the filtrate was concentrated under reduced pressure to remove the acetone. The resulting residue and broth filtrate were combined and extracted three times with ethyl acetate and then concentrated in vacuo. The ethyl acetate-soluble portion was chromatographed on Sephadex LH-20 eluted with methanol. Antioxidant fractions showing free radical-scavenging activity were combined and separated by a preparative HPLC equipped Cosmosil $\mathrm{C}_{18}$ column (Nacalai Tesque, Kyoto, Japan) (i.d. $10 \times 150 \mathrm{~mm}$ ) with $50 \%$ aqueous methanol as an eluent with a flow rate of $3 \mathrm{ml} \mathrm{min}^{-1}$ to afford four active compounds 1 (6.7 mg), 2 (4.1 mg), 3 (1.3 mg) and 4 (3.4 mg). Compound 1 was identified as spirobenzofuran by the comparison of its spectroscopic data with the previous literature. ${ }^{13}$
Compound 2 was obtained as a white powder with the specific rotation value of $+11.8^{\circ}\left([\alpha]_{D} ; 20^{\circ} \mathrm{C}, 7.2 \mathrm{mg} \mathrm{ml}^{-1}, \mathrm{MeOH}\right)$ and exhibited UV maxima ( $\log \varepsilon$ ) at 305 (3.7), 258 (sh, 2.3) and 204 (4.2). Its MW was established as 246 by a molecular ion peak at $\mathrm{m} / \mathrm{z} 246$ $[\mathrm{M}]^{+}$in the EI mass, and the molecular formula was determined as $\mathrm{C}_{15} \mathrm{H}_{18} \mathrm{O}_{3}$ by high-resolution EI mass $(\mathrm{m} / z \text { 246.1254 [M] }]^{+}, \Delta-0.2$ $\mathrm{mmu})$. The ${ }^{1} \mathrm{H}$ NMR spectrum of 2 showed signals due to two
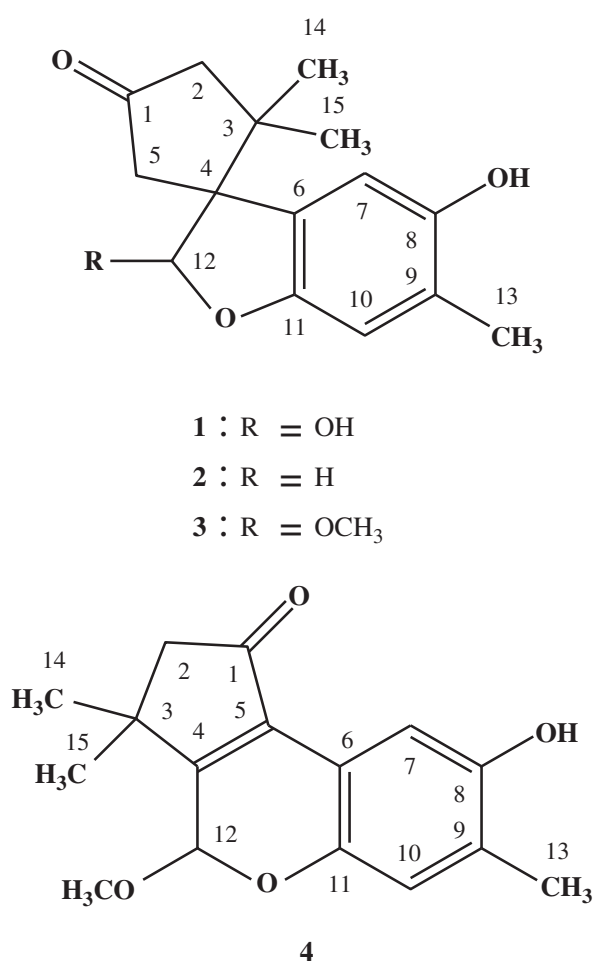

Figure 1 Structures of compounds $1-4$.

${ }^{1}$ Division of Biotechnology and Advanced Institute of Environment and Bioscience, College of Environmental and Bioresource Sciences, Chonbuk National University, Iksan, Korea and ${ }^{2}$ Rural Development Administration, Suwon, Korea

Correspondence: Professor B-S Yun, Division of Biotechnology and Advanced Institute of Environment and Bioscience, College of Environmental and Bioresource Sciences, Chonbuk National University, Gobong-ro 79, Iksan 570-752, Korea.

E-mail: bsyun@jbnu.ac.kr

Received 6 May 2014; revised 20 October 2014; accepted 27 October 2014; published online 17 December 2014 
Table $1{ }^{1} \mathrm{H}$ and ${ }^{13} \mathrm{C}$ NMR spectral data for compounds $2-4$ in $\mathrm{CD}_{3} \mathrm{OD}$

\begin{tabular}{|c|c|c|c|c|c|c|}
\hline \multirow[b]{2}{*}{ No. } & \multicolumn{2}{|r|}{2} & \multicolumn{2}{|r|}{3} & \multicolumn{2}{|r|}{4} \\
\hline & $\delta_{C}$ & $\delta_{H}(\mathrm{~J}$ in $\mathrm{Hz})$ & $\delta_{C}$ & $\delta_{H}(\mathrm{~J}$ in $\mathrm{Hz})$ & $\delta_{C}$ & $\delta_{H}$ \\
\hline 1 & 218.9 & & 219.2 & & 206.8 & \\
\hline 2 & 53.5 & $2.38(\mathrm{~s})^{\mathrm{b}}$ & 53.4 & $\begin{array}{l}2.33(\mathrm{~d}, J=18.5) \\
2.38(\mathrm{~d}, J=18.5)\end{array}$ & 53.6 & $2.48(\mathrm{~s})$ \\
\hline 3 & 42.9 & & 42.7 & & 40.0 & \\
\hline 4 & 57.2 & & 61.0 & & 167.3 & \\
\hline 5 & 49.0 & $\begin{array}{l}2.55(\mathrm{~d}, J=19.2) \\
2.73(\mathrm{~d}, J=19.2)\end{array}$ & 43.8 & $\begin{array}{l}2.46(\mathrm{~d}, J=19.2) \\
2.96(\mathrm{~d}, J=19.2)\end{array}$ & 130.8 & \\
\hline 6 & 128.8 & & 128.2 & & 115.5 & \\
\hline 7 & 112.4 & $6.54(\mathrm{~s})$ & 111.8 & $6.48(\mathrm{~s})$ & 110.5 & 7.52 (s) \\
\hline 8 & 150.3 & & 150.6 & & 151.2 & \\
\hline 9 & 126.2 & & 126.2 & & 128.1 & \\
\hline 10 & 111.8 & $6.52(\mathrm{~s})$ & 112.7 & $6.56(\mathrm{~s})$ & 119.5 & $6.80(\mathrm{~s})$ \\
\hline 11 & 154.7 & & 152.2 & & 144.3 & \\
\hline 12 & 79.7 & $\begin{array}{l}4.11(\mathrm{~d}, J=9.6) \\
4.75(\mathrm{~d}, J=9.6)\end{array}$ & 110.2 & $5.47(\mathrm{~s})$ & 96.3 & $5.85(\mathrm{~s})$ \\
\hline 13 & 16.6 & $2.13(\mathrm{~s})$ & 16.6 & $2.15(\mathrm{~s})$ & 16.5 & 2.17 (s) \\
\hline 14 & 24.7 & 0.96 (s) & 24.9 & $0.90(\mathrm{~s})$ & 27.8 & $1.31(\mathrm{~s})$ \\
\hline 15 & 24.0 & $1.09(\mathrm{~s})$ & 24.0 & $1.08(\mathrm{~s})$ & 27.6 & $1.35(\mathrm{~s})$ \\
\hline $\mathrm{OCH}_{3}$ & & & 56.2 & $3.46(\mathrm{~s})$ & 55.7 & $3.52(\mathrm{~s})$ \\
\hline
\end{tabular}

a NMR spectra were recorded at $600 \mathrm{MHz}$ for ${ }^{1} \mathrm{H}$ and $150 \mathrm{MHz}$ for ${ }^{13} \mathrm{C}$.

bProton multiplicity and coupling constants in parenthesis.

aromatic methine singlets at $\delta 6.54$ and 6.52 , a methylene at $\delta$ $4.11 / 4.75$ in the furan ring, two methylenes at $\delta 2.38$ and 2.55/2.73 in the cyclopentanone moiety, and three methyl groups at $\delta 2.13,1.09$ and 0.96 (Table 1). In the ${ }^{13} \mathrm{C}$ NMR spectrum, a carbonyl carbon at $\delta$ 218.9, two oxygenated $\mathrm{sp}^{2}$ quaternary carbons at $\delta 154.7$ and 150.3, two $\mathrm{sp}^{2}$ quaternary carbons at $\delta 128.8$ and 126.2 , two $\mathrm{sp}^{2}$ methine carbons at $\delta 112.4$ and 111.8, a oxygenated methylene carbon at $\delta$ 79.7, two methylene carbons at $\delta 53.5$ and 49.0, two quaternary carbons at $\delta 57.2$ and 42.9, and three methyl carbons at $\delta 24.7,24.0$ and 16.6 were evident. All proton-bearing carbons were assigned by the HMQC spectrum. The chemical structure was determined by the $\mathrm{HMBC}$ spectrum, which showed long-range correlations from $\mathrm{H}-2$ to C-1, C-3 and C-4, from H-5 to C-1, C-3, C-4, C-6 and C-12, and from $\mathrm{H}-12$ to $\mathrm{C}-3, \mathrm{C}-4, \mathrm{C}-5, \mathrm{C}-6$ and C-11. These correlations established the presence of a spirocyclic ring system in $2 .{ }^{13}$ In addition, the long-range correlations from $\mathrm{H}-14$ and $\mathrm{H}-15$ to $\mathrm{C}-2, \mathrm{C}-3$ and C-4 suggested that two methyl groups should be placed on the cyclopentanone moiety. The long-range correlations from the aromatic methine proton of $\mathrm{H}-7$ to $\mathrm{C}-4, \mathrm{C}-9$ and $\mathrm{C}-11$, and from the aromatic methine proton of $\mathrm{H}-10$ to $\mathrm{C}-6, \mathrm{C}-8$ and $\mathrm{C}-13$ were evident (Figure 2). Therefore, the structure of $\mathbf{2}$ was determined to be a new derivative of spirobenzofuran lacking an oxygen molecule at the C-12 position, as shown Figure 2, and this compound was named deoxyspirobenzofuran.

Compound 3 was obtained as a white powder with the specific rotation value of $-186.9\left([\alpha]_{\mathrm{D}} ; 20^{\circ} \mathrm{C}, 13.6 \mathrm{mg} \mathrm{ml}^{-1}, \mathrm{MeOH}\right)$, and its UV maxima $(\log \varepsilon)$ at 301.0 (3.7), 258.0 (sh, 2.9) and 204.5 (4.3) suggested that this compound was a spirobenzofuran derivative. It exhibited a molecular ion peak at $m / z 276[\mathrm{M}]^{+}$in the EI-MS, and the molecular formula was determined as $\mathrm{C}_{16} \mathrm{H}_{20} \mathrm{O}_{4}$ by hig-resolution EI-MS $\left(m / z 276.1358\left[\mathrm{M}^{+}, \Delta-0.4 \mathrm{mmu}\right)\right.$, which was in agreement with the ${ }^{1} \mathrm{H}$ and ${ }^{13} \mathrm{C}$ NMR spectra. The ${ }^{1} \mathrm{H}$ and ${ }^{13} \mathrm{C}$ NMR spectral data of 3 was similar to those of 2, except for the disappearance of a
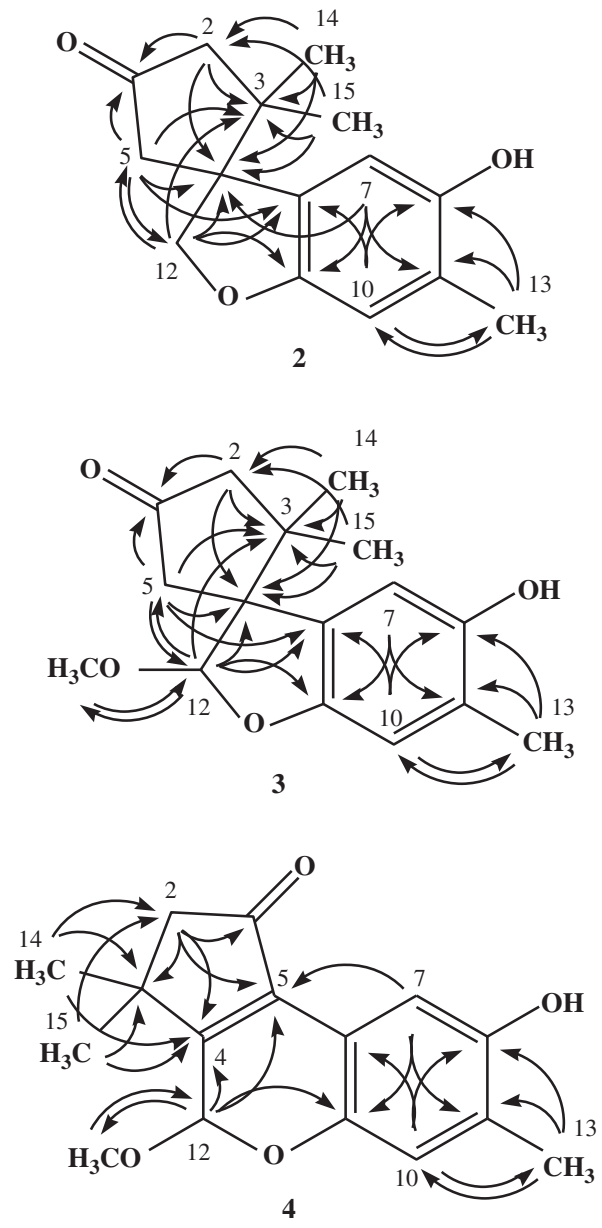

$\longrightarrow$ : HMBC correlations

Figure 2 HMBC correlations of compounds 2-4.

methylene signal and the presence of acetal $\left(\delta_{\mathrm{H}} 5.47, \delta_{\mathrm{C}} 110.2\right)$ and methoxyl $\left(\delta_{\mathrm{H}} 3.46, \delta_{\mathrm{C}} 56.2\right)$ signals in 3 (Table 1). All proton-bearing carbons were assigned by the HMQC spectrum, and the structure was determined by HMBC spectrum. HMBC (Figure 2) revealed that the cyclopentanone moiety and aromatic ring system of $\mathbf{3}$ was the same as that of compound 2. The long-range correlations from H-5 to C-12 ( $\delta$ 110.2) and from H-12 ( $\delta$ 5.47) to C-3, C-4, C-5, C-6, C-11 and a methoxyl carbon at $\delta 56.2$ were evident. These correlations implied that C-12 of the furan moiety was substituted by a methoxyl group. Therefore, compound 3 was named methoxyspirobenzofuran.

Compound $\mathbf{4}$ was obtained as a white powder with the specific rotation value of $-4.8^{\circ}\left([\alpha]_{\mathrm{D}} ; 20^{\circ} \mathrm{C}, 6.6 \mathrm{mg} \mathrm{ml}-1, \mathrm{MeOH}\right)$ and showed UV maxima ( $\log \varepsilon$ ) at 335 (3.3), 315 (sh, 3.2), 263 (3.8), 233 (sh, 3.8), and 209 (4.4) nm. It exhibited a molecular ion peak at $\mathrm{m} / \mathrm{z} 274[\mathrm{M}]^{+}$in the EI-MS, and the molecular formula was determined as $\mathrm{C}_{16} \mathrm{H}_{18} \mathrm{O}_{4}$ by high resolution EI-MS $(\mathrm{m} / z 274.1201$ $[\mathrm{M}]^{+}, \Delta-0.4 \mathrm{mmu}$ ), which was in agreement with the ${ }^{1} \mathrm{H}$ and ${ }^{13} \mathrm{C}$ NMR spectra. The ${ }^{1} \mathrm{H}$ NMR spectrum of 4 in $\mathrm{CD}_{3} \mathrm{OD}$ showed signals due to two aromatic methines at $\delta 7.52$ and 6.80 , an oxygenated methine at $\delta 5.85$, a methoxy proton at $\delta 3.52$, a methylene at $\delta 2.48$ and three methyls at $\delta 2.17,1.35$ and 1.31. In the ${ }^{13} \mathrm{C}$ NMR spectrum, a carbonyl carbon at $\delta 206.8$, two oxygenated $\mathrm{sp}^{2}$ quaternary carbons at $\delta 151.2$ and 144.3, four $\mathrm{sp}^{2}$ quaternary carbons at $\delta 167.3,130.8$, 128.1 and 115.5 , two $\mathrm{sp}^{2}$ methine carbons at $\delta 119.5$ and 110.5 , an 


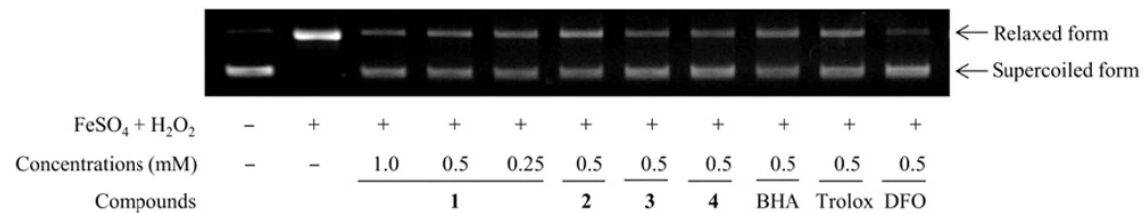

Figure 3 Protective effects of compounds 1-4 against plasmid DNA breakage by the Fenton reaction between ferrous and hydrogen peroxide.

Table 2 Free radical-scavenging activities of compounds 1-4

\begin{tabular}{|c|c|c|}
\hline \multirow[b]{2}{*}{ Compounds } & \multicolumn{2}{|c|}{$I_{50}(\mu M)^{a}$} \\
\hline & ABTS & $D P P H$ \\
\hline 1 & $52.4 \pm 6.0$ & $125.8 \pm 5.9$ \\
\hline 2 & $64.1 \pm 3.1$ & $226.9 \pm 36.5$ \\
\hline 3 & $58.4 \pm 3.1$ & $335.7 \pm 15.8$ \\
\hline 4 & $87.9 \pm 4.3$ & $834.3 \pm 93.5$ \\
\hline $\mathrm{BHA}$ & $45.3 \pm 2.3$ & $137.0 \pm 3.8$ \\
\hline Trolox & $57.0 \pm 6.2$ & $103.1 \pm 3.2$ \\
\hline
\end{tabular}

Abbreviations: ABTS, 2,2'-azinobis[3-ethylbenzothiazoline-6-sulfonate]; DPPH, 1,1-diphenyl-2picrylhydrazyl.

BHA (butylated hydroxyanisole) and Trolox were used as positive controls.

aResults presented as the mean $(n=3) \pm$ s.d.

oxygenated methine carbon at $\delta 96.3$, a methoxy carbon at $\delta$ 55.7, a methylene carbon at $\delta 53.6$, a quaternary carbon at $\delta 40.0$, and three methyl carbons at $\delta 27.8,27.6$ and 16.5 were evident. All protonbearing carbons were established by the HMQC spectrum. The chemical structure was determined by $\mathrm{HMBC}$ spectrum, which showed the long-range correlations from $\mathrm{H}-2$ to $\mathrm{C}-1, \mathrm{C}-3, \mathrm{C}-4$ and C-5 and from $\mathrm{H}-14$ and $\mathrm{H}-15$ to $\mathrm{C}-2, \mathrm{C}-3$ and $\mathrm{C}-4$, suggesting the presence of a cyclopentenone moiety substituted with two methyl groups. The long-range correlations from the aromatic methine proton of $\mathrm{H}-7$ to $\mathrm{C}-5, \mathrm{C}-9$ and $\mathrm{C}-11$, and the aromatic methine proton of $\mathrm{H}-10$ to $\mathrm{C}-6, \mathrm{C}-8$ and $\mathrm{C}-13$ were evident. An acetal proton $(\mathrm{H}-12)$ at $\delta 5.85$ showed long-range correlations to C-4, C-5 and $\mathrm{C}-11$, establishing the benzopyran moiety. Finally, the long-range correlation from the methyl protons at $\delta 3.52$ to $\mathrm{C}-12$ connected the methoxyl group to C-12 of the pyran ring. Therefore, the structure of 4 was determined to be a new spirobenzopyran derivative.

The antioxidant activity of compounds $\mathbf{1 - 4}$ was evaluated by the DPPH (1,1-diphenyl-2-picrylhydrazyl) radical and ABTS (the 2,2azinobis[3-ethylbenzothiazoline-6-sulfonate]) radical-scavenging assay method. ${ }^{14}$ The DPPH and ABTS radical-scavenging activities were defined as the amount of antioxidant necessary to decrease the initial radical concentration by $50 \%\left(\mathrm{IC}_{50}\right)$. Compounds 1 and 3 showed potent antioxidant activity with $\mathrm{IC}_{50}$ values of 52.4 and $58.4 \mu \mathrm{M}$, respectively, in the ABTS radical-scavenging assay, and were comparable with Trolox $\left(\mathrm{IC}_{50}, 57.0 \mu \mathrm{M}\right)$ and BHA ( $\left.\mathrm{IC}_{50}, 45.3 \mu \mathrm{M}\right)$ (Table 2). However, compounds 2 and 4 with $\mathrm{IC}_{50}$ values of 64.1 and $87.9 \mu \mathrm{M}$, respectively, were less active than Trolox and BHA. In the DPPH radical-scavenging assay, compound $\mathbf{1}$ exhibited potent activity with an $\mathrm{IC}_{50}$ value of $125.8 \mu \mathrm{M}$, which was similar to BHA $\left(\mathrm{IC}_{50}, 137.0 \mu \mathrm{M}\right)$ and less active than Trolox $\left(\mathrm{IC}_{50}, 103.1 \mu \mathrm{M}\right)$. Compounds 2 and 3 showed moderate DPPH radical-scavenging activities (Table 2).
Consequently, compounds 1, 2 and 3 with furan moieties exhibited more potent antioxidant activity than compound $\mathbf{4}$ with a pyran moiety. The formation of hydroxyl radicals from the Fenton reaction between ferrous and hydrogen peroxide was measured using plasmid DNA single-strand breakage (SSB). The protective effect of compounds 1-4 against DNA damage by the Fenton reaction was evaluated using the ferrous and hydrogen peroxide-induced DNA SSB method. ${ }^{15}$ All compounds tested inhibited the DNA SSB induced by the Fenton reaction in a dose-dependent manner (Figure 3). Activity was comparable with BHA and Trolox, but less active than deferoxamine mesylate salt (an iron chelator).

\section{ACKNOWLEDGEMENTS}

This work was supported by a grant from the Korea Forest Service and by Basic Science Research Program through the National Research Foundation of Korea (NRF) funded by the Ministry of Education, Science and Technology (2013062358), Republic of Korea. This paper was supported by research funds of Chonbuk National University in 2014.

1 Diplock, A. T. et al. Functional food science and defence against reactive oxidative species. Br. J. Nutr. 80, 77-112 (1998).

2 Halliwell, B. \& Gutteridge, J. M. C. Free Radicals in Biology and Medicine 936 (New York: Oxford, 1999).

3 Sanderson, T. H., Reynolds, C. A., Kumar, R., Przyklenk, K. \& Hüttemann, M. Molecular mechanisms of ischemia-reperfusion injury in brain: pivotal role of the mitochondrial membrane potential in reactive oxygen species generation. Mol. Neurobiol. 47, 9-23 (2013).

4 Shah, A. A. \& Sinha, A. A. Oxidative stress and autoimmune skin disease. Eur. J. Dermatol. 23, 5-13 (2013).

5 Stadler, K. Oxidative stress in diabetes. Adv. Exp. Med. Biol. 771, 272-287 (2012).

6 Nagmoti, D. M., Khatri, D. K., Juvekar, P. R. \& Juvekar, A. R. Antioxidant activity and free radical-scavenging potential of Pithecellobium dulce Benth seed extracts. Free Rad. Antiox. 2, 37-43 (2012).

7 Bu'Lock, J. D. \& Darbyshire, J. Lagopodin metabolites and artefacts in cultures of Coprinus. Phytochemistry 15, 2004 (1976).

8 Pettit, G. R. et al. Antineoplastic agents. 556. Isolation and structure of coprinastatin 1 from Coprinus cinereus. J. Nat. Prod. 73, 388-392 (2010).

9 Liu, Y. et al. Guanacastane-type diterpenoids with cytotoxic activity from Coprinus plicatilis. Bioorg. Med. Chem. Lett. 22, 5059-5062 (2012).

10 Ou, Y. X., Li, Y. Y., Qian, X. M. \& Shen, Y. M. Guanacastane-type diterpenoids from Coprinus radians. Phytochemistry 78, 190-196 (2012).

11 Liu, Y. J., Liu, Y. \& Zhang, K. Q. Xanthothone, a new nematicidal N-compound from Coprinus xanthothrix. Chem. Nat. Compd. 44, 203-205 (2008).

12 Kettering, M., Valdivia, C., Sterner, O., Anke, H. \& Thines, E. Heptemerones A-G, seven novel diterpenoids from Coprinus heptemerus: producing organism, fermentation, isolation and biological activities. J. Antibiot. 58, 390-396 (2005).

13 Kleinwächter, P., Schlegel, B., Dörfelt, H. \& Gräfe, U. Spirobenzofuran, a new bioactive metabolite from Acremonium sp. HKI 0230. J. Antibiot. 54, 526-527 (2001).

14 Lee, I. K., Jung, J. Y., Kim, Y. S., Rhee, M. H. \& Yun, B. S. p-Terphenyls from the fruiting bodies of Paxillus curtisii and their antioxidant properties. Bioorg. Med. Chem. 17, 4674-4680 (2009).

15 Lee, I. K., Jang, Y. W., Yu, S. H. \& Yun, B. S. New triterpene glucosides, oligoporins A - C, from Oligoporus tephroleucus protect DNA from Fenton reaction. Bioorg. Med. Chem. Lett. 17, 4906-4909 (2007). 